\title{
Human Capital Convergence in Greece: A Panel Data Analysis
}

George Liaskos and Christos T. Papadas

\begin{abstract}
The neoclassical growth model has been supported by a large amount of regional and cross-country studies providing evidence of $\beta$-convergence. Nevertheless, it faces theoretical and empirical challenges which are still the subject of research on the dynamics of growth. Consideration of human capital accumulation has strengthened the theoretical foundations of the model, especially its open economy version. It has also improved the explanatory power of the model and its usefulness in quantitative analysis. Human capital accumulation accounts for that part of observed per capita income and output disparities, not explained adequately by the initial approach. Newer versions of neoclassical growth modeling imply clearly that the process of growth and convergence depends heavily on human capital accumulation and convergence. This study investigates regional human capital convergence in Greece during the period 1971-2001, for the census years of which necessary data are available. Following the usual practice in the literature, human capital quality is expressed in terms of educational achievement. Panel data econometric analysis is conducted using census year data for the Greek prefectures (NUTS III areas). The existence of human capital $\beta$-convergence is examined. Changes in the distributions of educational achievement, using different criteria, are also examined in order to see if actual convergence occurs. Results show that both space and time effects are significant and so is the established conditional $\beta$-convergence. Nevertheless, actual convergence is not achieved over the examined period and the dispersion of the observed human capital distributions has been increasing.
\end{abstract}




\section{Introduction}

A vast amount of quantitative results confirms the existence of $\beta$-convergence, either conditional or absolute, for a variety of countries and regions within and across countries. This conclusion holds with respect to per capita incomes and productivity indices. Existence of $\beta$-convergence is not always accompanied by a reduction in the dispersion of the observed distributions of per capita income and productivity indices.

Despite the evidence on $\beta$-convergence and the validity of neoclassical growth modeling, there are certain observed facts of the growth and convergence process which cannot be adequately accounted for by the traditional approaches. Modifications and extensions of the original Solow-Swan model offer more adequate and satisfactory interpretations of key observations and measurements. Considerations of human capital and its accumulation play a most essential role in that. Human capital quality issues had already been raised and discussed in the $\mathrm{AK}$ and endogenous growth models, where the absence of a steady state due to constant average returns of capital or a changing steady state respectively, explain the continuity of the growth process over long periods.

Statistical data and calculations regarding the production elasticity of capital and its share on national income create some of the validity problems encountered in the original Solow type models. In addition, theoretical and empirical challenges emerging from the open economy neoclassical growth model of Barro, Mankiw, and Sala-i-Martin (1995) and its implications on regional convergence can be faced taking into account quality differences and the accumulation of human capital. The significance of the latter has become of such importance, that if the concept of capital in the original models is broadened to include both physical and human capital (instead of the first only, with a homogeneous labor input), the neoclassical growth model is in position to face most of its empirical challenges (Mankiw, Romer, and Weil, 1992).

Based on these results, some authors (e.g. Mankiw, 1995) see the inclusion of both, human and physical capital as a satisfactory theoretical and quantitative answer to criticisms against the traditional exogenous technology approach. Proponents of the endogenous technology growth theories such as Romer (1986) and Lucas (1988) would probably disagree. Romer (1995) in particular, argues that accounting better and sufficiently for empirical facts such as the capital share in national income, does not provide a theoretical rescue for the traditional neoclassical approach.

Developments in growth modeling provide insights into the regional convergence process of human capital itself and the way it affects the process of income or productivity convergence. Therefore, quantitative analysis of human capital convergence, its accumulation, and its contribution to economic growth and convergence, have become of particular research interest. This study investigates firstly the existence of $\beta$-convergence for human capital between the Greek prefectures (NUTS III areas). Human capital is approximated by educational achievement measured in two ways: The percentage share of population with completed secondary education, and the percentage share of population with completed university education. Compatible data at the level of 51 prefectures are available for the census years of the period 1971-2001. The investigation and 
measurement of $\beta$-convergence is based on panel data econometric analysis. This allows for consideration of unobserved spatial and time effects using cross sectional observations for all available periods.

The existence of actual convergence for the two human capital measures, as expressed by the dispersion of their distributions for each of the four census years, is also investigated. Dispersion is measured using the suggested in the literature, alternative approaches and concepts of $\sigma$-convergence, Q-convergence, and the pairwise differences between observations.

\section{Human Capital in Growth Modeling}

In the usually adopted production function of the Cobb-Douglas form with constant returns to scale, income shares are given by production elasticities which are the exponents of the production function. Such a production function in the original models takes the form: $Y=A K^{a}\left(L e^{\chi t}\right)^{1-a}$ where $\mathrm{A}$ is an exogenous technology variable, $\mathrm{K}$ capital, $\mathrm{L}$ labor and $\chi$ its growth rate in units of efficiency. Applications and estimations of such production functions with a homogeneous labor and a common exogenous technology over different countries and regions, have led to a lack of compatibility between model predictions and some observed data. There are two such main issues (Coulombe and Tremblay, 2001).

One issue relates to magnitudes of income differentials. Given the assumptions above the steady state of output per capita is determined by the saving rate and population growth rate. Statistical information confirms that the saving rate is higher and the population growth rate lower in richer than in poorer countries. Even though this accounts for some of the gap in per capita incomes between richer and poorer country groups, it cannot account for all of the large gaps observed. Moreover, due to diminishing returns the rate of return for capital should be higher in poorer countries. This does occur in practice but to a much lesser extend than the traditional estimated models would imply. Such discrepancies are effectively faced if the concept of capital includes not only physical capital but human capital as well.

The limited concept of capital in traditional theoretical formulations was prompted, among others, for the reason that it is very difficult to collect accurate data on human capital and its accumulation. The latter includes education, on the job training, and experience. The measurement of professional experience and on the job training is hard and there is a shortage of data. As a result and since the contribution of human capital accumulation is incorporated into wages, information on capital income share refers to physical capital only and in the systems of national accounts it, generally speaking, is given by the national income share of profits.

If a production function as proposed by Barro, Mankiw, and Sala-i-Martin (1995) is adopted, then $Y=A K^{a} H^{n}\left(L e^{x t}\right)^{1-a-n}$ where $\mathrm{H}$ is a human capital accumulation variable and $\mathrm{n}$ is its output elasticity. Since now exponents of inputs give their share in national income, $\mathrm{n}$ is also the steady-state national income share of the return to human capital accumulation. This return, not directly observed, is incorporated into wages. Broadening the concept of capital in such a way and accounting for $\mathrm{H}$ has been very effective in accounting for the output elasticity and income share of the 
broadened capital in US and for most of the stylized facts of economic development, related to income and broadened capital return differentials (Mankiw, 1995).

Another issue that accounting for $\mathrm{H}$ faces effectively, concerns the conclusions on regional convergence in the open economy neoclassical growth model. In an open economy model the equality between domestic savings and domestic investment no longer holds. With perfect capital mobility and unlimited borrowing, the result will be capital flows directed towards economies with lower capital per unit of labor. As a consequence, the economies will immediately achieve their steady state. Undoubtedly, this theoretical conclusion is incompatible with observed and stylized facts about development.

Within regions or states of the same country with a free market system and the same legal and institutional framework, one would expect that free capital mobility is a realistic assumption even though its implications depend on the particular growth modeling. Moreover, the empirical testing of this hypothesis is difficult. Feldstein and Horioka (1980) proposed a test based on the correlation between domestic savings and investment. A strong positive correlation indicates limitations to capital mobility. There have been criticisms (Barro, Mankiw, and Sala-i-Martin, 1995) that in a neoclassical model with capital mobility and constraints on borrowing for the purposes of human capital accumulation, the logic of the Feldstein-Horioka test holds only at the steady state across economies which differ only at their rates of taxation. However, the test has been used (eg Brown 1992, Helliwell and McKitrick 1999), and capital was indeed found to exhibit higher mobility between the provinces of Canada than between the OECD countries as whole).

The obvious way to reconcile an open economy model and the theoretical result of each economy's convergence to its steady state at an infinite rate, with economic experience, is the imposition of constraints in international borrowing (eg. Cohen and Sachs, 1986). With human capital accumulation in the model, a new way to reconcile theory and facts is offered by introducing a constraint on international borrowing for purposes of such an accumulation. The nature of human capital makes such an assumption realistic since unlike physical capital, as Barro, Mankiw, and Sala-iMartin, (1995) argue, investment in human capital is generally financed with domestic savings. Borrowing from abroad with human capital or non-expert labor as collateral is usually impossible and the same is true for borrowing from domestic capital markets since such loans are not usually secure. Unless government finances investment on human capital, most of its accumulation needs to be financed from personal or family sources.

The inclusion of human capital in the production function with a separate consideration for physical capital and the introduction of the constraint on the financing of human capital accumulation, leads to the important implication that the dynamics of this accumulation process affects the path of economic variables towards their steady state. Moreover, the convergence speed of per capita income and per capita physical capital towards their steady states is determined and equals the speed of human capital convergence to its steady state. 


\section{The Role of Human Capital in Regional Economic Convergence}

As a result of the above discussion it can be argued that even if physical capital displays perfect mobility in the open economy model, when human capital per unit of labor is below its steady state, convergence of per capita (or per unit of labor) income to its steady state is gradual. In traditional modeling with physical capital and a homogeneous labor as inputs, poorer regions with lower capital per unit of labor at the initial state, display higher marginal products of capital than the richer economies and capital flows should take place from the latter to the former.

Barro, Mankiw, and Sala-i-Martin (1995) show however that in their framework, the relative scarcity of human capital in poorer regions results in a fast decrease in the marginal product of physical capital. As a consequence and unlike the result of traditional modeling, capital's marginal product is the same in poorer and richer regions during the transition to each economy's steady state. In addition, Barro and Sala-i-Martin (1995) show that now the average physical capital remains the same during convergence to steady state. This, as Coulombe and Tremblay (2001) argue is actually one of Kalder's (1964) stylized facts about development.

If it is assumed that investment in education is not financed exclusively by domestic savings of regions or states but by a greater authority through taxation and resource redistribution (eg the central government), the process of regional growth is again driven by the process of human capital accumulation. This holds even when maintaining in an open economy model, the assumption of international free capital mobility for the financing of physical capital accumulation. The incentive to invest in human capital accumulation in the poorer regions will determine the speed of convergence between poorer and richer regions.

In the original Barro and Sala-i-Martin (1992) model, at time t of the transition process towards the steady state, income per effective unit of labor $\mathrm{y}_{\mathrm{t}}$ is given by:

$$
\ln y_{t}=e^{-\beta t} \ln y_{0}+\left(1-e^{-\beta t}\right) \ln y^{*}
$$

where $\mathrm{y}_{0}$ is the initial state and $\mathrm{y}^{*}$ is the steady state. During the period between $\mathrm{t}_{0}$ and $\mathrm{t}_{1}$ for regions $\mathrm{i}$ with the same steady state and the same rate of technological progress $\chi_{i}=\chi$, the model yields:

$$
\frac{1}{T} \ln \left(\frac{y_{i, t_{0}+T}}{y_{i, t_{0}}}\right)=B-\left(\frac{1-e^{-\beta t}}{T}\right) \ln \left(y_{i, t_{0}}\right)+u_{i, t_{0} t_{0}+T}
$$

where $\mathrm{T}$ is the number of periods between $\mathrm{t}_{0}$ and $\mathrm{t}_{0}+\mathrm{T}$ which the y's refer to, $u_{i, t_{0} t_{0}+T}$ is a distributed lag of error terms $u_{i t}$ between $t_{0}$ and $t_{0}+\mathrm{T}$, $B=x+\left[\left(1-e^{-\beta t}\right) / T\right]\left[\ln \left(y^{*}\right)+\chi t_{0}\right]$, and $\beta$ is the speed of convergence. $\mathrm{B}$ can shift as $\mathrm{t}_{0}$ changes due to the technology trend but is independent of the cross sectional unit $\mathrm{i}$ since a common $\mathrm{y}^{*}$ and $\chi$ are assumed. The model predicts that $\beta>0$ which means that poorer economies tend to grow faster than richer economies at the initial state. This is known as $\beta$-convergence and using cross-section data it can be examined estimating (2) as:

$$
\frac{1}{T} \ln \left(\frac{y_{i, t_{0}+T}}{y_{i, t_{0}}}\right)=a+b \ln \left(y_{i, t_{0}}\right)+u_{i, t_{0} t_{0}+T}
$$


where $\alpha=\mathrm{B}$ and $b=-\frac{1-e^{-\beta t}}{T}$. Then, $\beta$-convergence occurs if $\mathrm{b}<0$ and the lower the initial state, the greater the average rate of growth.

The use of (3) is associated with what is called absolute $\beta$-convergence but the model is actually predicting conditional $\beta$-convergence exactly because of the assumptions of common $\chi$ and $y^{*}$. If the steady states differ, (3) is estimated adding additional constraint variables which cause the differences or capture the effect of factors that cause the differences, between rates of technical change and/or steady states. In that case under conditional $\beta$-convergence, each cross sectional unit i converges to its own steady state. Obviously, if the assumptions of common $\chi$ and $\mathrm{y}^{*}$ hold there is no distinction in practice between absolute and conditional convergence.

In the open economy model with human capital, with a Cobb-Douglas production function, and an exogenous world wide interest rate, the production function can take the form (Barro, Mankiw, and Sala-i-Martin, 1995):

$$
y=B h^{\frac{n}{1-a}}
$$

where $\mathrm{h}$ is human capital $(\mathrm{H})$ per unit of effective labor and $\mathrm{B}$ is a constant, independent of capital per unit of effective labor (capital/labor ratio) and a function of exogenous variables. With constant returns to scale we have $\alpha+\eta<1$ while capital accumulation is subject to decreasing returns. With a credit constraint on human capital accumulation, the open economy model behaves like a closed economy model where $\eta /(1-\alpha)$ is the income share of the broadly defined capital (physical and human).

Using (1) and (4) we can derive an expression describing the movement of $\mathrm{h}$ towards its steady state $h^{*}$ :

$$
\ln h_{t}=e^{-\beta t} \ln h_{0}+\left(1-e^{-\beta t}\right) \ln h^{*}
$$

As with output per unit of labor $y$, the ratio human capital/labor at any time $t$ is a weighted average of the initial $\left(\mathrm{h}_{0}\right)$ and steady states. Moreover, as with $\mathrm{y}$ and with a common steady state $\mathrm{h}^{*}$ for all regions i we can derive:

$$
\frac{1}{T} \ln \left(\frac{h_{i, t+T}}{h_{i, t_{0}}}\right)=a+b \ln \left(h_{i, t_{0}}\right)+\varepsilon_{i, t_{0} t_{0}+T}
$$

where $b=-\frac{\left(1-e^{-\beta_{h} T}\right)}{T}$ and $\beta_{\mathrm{h}}$ is the speed of convergence towards the common steady state. Again, equation (6) is referred to as the absolute convergence model but in fact the equation holds under the condition of a common steady state and if this assumption is violated, (6) is estimated with additional variables that cause differences in steady states. Conditional convergence $(b<0)$ implies that the economies converge to their own steady states $\mathrm{h}^{*}$ and $\mathrm{y}^{*}$ while if the steady states are indeed common for all considered economies, the concepts of absolute and conditional convergence are not distinguished anyway.

The similarity in the equations of transition dynamics (1) and (5) and the derived models used in empirical applications (3) and (6) reflect the fact that the physical capital/labor ratio follows the transitory dynamics of human capital accumulation. 


\title{
Changes in Regional Distributions of Human Capital
}

\author{
$\sigma$-convergence, dispersion, and clustering approaches
}

$\beta$-convergence of human capital per unit of labor does not imply actual converge if the criterion for actual convergence is the dispersion of regional distributions of the relevant index over a period. An obvious measure of dispersion is the standard deviation of a regional distribution $(\sigma)$ around its mean, and if within a period $\sigma$ declines then $\sigma$-convergence is observed. As is the case with per capita incomes and other indices, $\beta$-convergence of human capital indices is a necessary but not sufficient condition for $\sigma$-convergence. On the other hand, $\beta$-divergence does imply $\sigma$ divergence.

Since the dispersion of a distribution does not dichotomize regions into rich and poor ones, other definitions and criteria were developed based on classification or clustering of the data in distributions (Quah 1996, Jones 1997). The problem now is that the dispersion of the distribution is not reflected in clusters and this extends to other, non parametric methods of clustering. Application of the concept of modal convergence for example, based on the non parametric bootstrap modality test of Silverman (1981), can lead to the conclusion of convergence (declining modes of the distribution) even though the standard deviation is in fact increasing (Bianchi, 1997).

There are numerous ways to measure dispersion and construct clusters and an additional criticism (Kang and Lee, 2005) is that both $\sigma$-convergence and clustering approaches are not invariant or equivariant to increasing monotonic transformations such as the logarithmic one. If for two distributions of a human capital index $h$ at consecutive times s and $\mathrm{t}, \sigma$-divergence is observed (i.e. $\sigma\left(\mathrm{h}_{\mathrm{s}}\right)<\sigma\left(\mathrm{h}_{\mathrm{t}}\right)$ ), it is possible to observe $\sigma$-convergence for the distribution of $\ln (h)$, that is, $\sigma\left(\ln h_{s}\right)>\sigma\left(\ln h_{t}\right)$. If in addition $\mathrm{f}(\mathrm{h})$ is a differentiable bimodal density for $\mathrm{h}$ with two modes $\mathrm{m}_{1}$ and $\mathrm{m}_{2}$, the transformed variable $\mathrm{z}=\ln (\mathrm{h})$ has density $\mathrm{g}(\mathrm{z})=\mathrm{f}\left(\mathrm{e}^{\mathrm{z}}\right) \mathrm{e}^{\mathrm{z}}$ and it can be shown easily that $\ln \left(\mathrm{m}_{1}\right)$ and $\ln \left(\mathrm{m}_{2}\right)$ are not the modes for the $\ln (\mathrm{h})$ distribution. In fact, $\mathrm{g}(\mathrm{z})$ does not have to be bimodal. Moreover, estimation of standard deviations are sensitive to outliers while non parametric approaches to modal convergence require several observed distributions which may not be available for a sufficient number of periods.

\section{Q-convergence}

Attempting to face the mentioned problems, Kang and Lee (2005) propose the concept and approach of Q-convergence which is based on the examination of the interquartile range (IQR) of a distribution and its changes over a period. As a measure of dispersion, IQRs have been used also in the study of income distribution (Deaton, 1997, etc.) while earlier versions of this approach are also referenced or found (Bianchi 1997, Beaudry, Collard, and Green, 2002). We shall denote as $\mathrm{L}_{\mathrm{Nt}}$ the sample lower quartile ( $25 \%$ quantile), $\mathrm{U}_{\mathrm{Nt}}$ the sample upper quartile ( $75 \%$ quantile) and $\mathrm{M}_{\mathrm{Nt}}$ the sample median quartile, $(\mathrm{i}=1, \ldots, \mathrm{N}$ and $\mathrm{t}=0,1)$. The population versions are respectively $\mathrm{L}_{\mathrm{N}}, \mathrm{U}_{\mathrm{N}}, \mathrm{M}_{\mathrm{N}}$.

By definition Q-convergence between $\mathrm{t}=0$ and $\mathrm{t}=1$ occurs if:

$$
U_{1}-L_{1}-\left(U_{0}-L_{0}\right)<0
$$


This simply says that convergence has occurred if, after ranking the observations from the highest to the lowest value, the range between the $75 \%$ quantile of observations and the $25 \%$ quantile of observations is diminished. If logarithmic values are used (i.e. $\ln \left(\mathrm{h}_{\mathrm{t}}\right)$ instead of $\mathrm{h}_{\mathrm{t}}$ ) Q-convergence of the distribution occurs if:

$$
\ln \left(U_{1}\right)-\ln \left(L_{1}\right)-\left\{\ln \left(U_{0}\right)-\ln \left(L_{0}\right)\right\}<0
$$

which in turn means that convergence occurs if:

$$
\frac{U_{1} / L_{1}}{U_{0} / L_{0}}<1 \text { or } \frac{U_{1}-L_{1}}{L_{1}}<\frac{U_{0}-L_{0}}{L_{0}}
$$

Convergence as in (8a) is called absolute Q-convergence while as in (8b) is called relative Q-convergence. The expressions are derived since the population lower and upper quartiles of $\ln \left(\mathrm{h}_{\mathrm{t}}\right)$ are respectively $\ln \left(\mathrm{L}_{\mathrm{t}}\right)$ and $\ln \left(\mathrm{U}_{\mathrm{t}}\right)$. This holds because for an increasing monotonic transformation $\mathrm{T}($.$) , the \alpha$ th quantile of $\mathrm{T}(\mathrm{h})$ is $\mathrm{T}(\alpha$ th quantile of $\mathrm{h}$ ). It is for this property that the Q-convergence approach is characterized as equivariant to increasing transformations. The property does not hold when the concept of $\sigma$-convergence is used since $\sigma(\ln h) \neq \ln (\sigma(h))$. Hence, it is argued, due to the quartiles' equivariance to such transformations, results based on IQR and the Qconvergence approach are more easily interpretable when log values are used, than in other approaches. However, as in the $\sigma$-convergence approach, level and logarithmic values using (8a) and (8b) can lead to opposite results (for absolute and relative Qconvergence or divergence).

In any case the IQR approach offers an alternative to the list of imperfect techniques studying distributional changes. Perhaps its main advantage when compared to the $\sigma-$ convergence concept is its insensitivity to outliers, leading to more robust conclusions. IQR changes can be used in a modal convergence approach using nonparametric techniques too, since the lower quartile and the upper quartile can reflect the centers of two clusters, as two modes do in a bimodal distribution. Statistical inferences on the significance of estimates can also be derived using asymptotic statistics and non parametric methods but they both require observed distributions for several time periods.

\section{Pair-wise convergence}

Following Lee, Pesaran, and Smith (1997) a way to examine convergence in a distribution over a period has been suggested and applied by Pesaran (2004). Considering all observations and taking all possible pairwise differences between them, two measures of average convergence or divergence are proposed:

$$
D_{t}^{2}=\frac{2}{N(N-1)} \sum_{i=1}^{N-1} \sum_{j=i+1}^{N}\left(h_{i t}-h_{j t}\right)^{2} \quad(9 \mathrm{a}) \text { and } \Delta_{t}=\frac{2}{N(N-1)} \sum_{i=1}^{N-1} \sum_{j=i+1}^{N}\left|h_{i t}-h_{j t}\right|
$$

It is also shown that if $\mathrm{s}^{2}$ is the variance of the observed distribution, then $D_{t}^{2}=2 s^{2}$ and $\Delta_{t}=($ Gini coefficient at time $\mathrm{t}) \times \bar{h}_{t}$ where $\bar{h}_{t}$ is the average of the distribution at time t. These results show that pairwise convergence is related to $\sigma$ convergence.

\section{Data and variables considered}

Human capital is only implicitly priced by the markets and this is one reason for the difficulty faced in its economic measurement. Objective and accurate measures of 
education, knowledge, experience and on the job training do not exist, because measurement of some of these factors is impossible or difficult to be conducted especially at regional levels. Data on population percentages which have completed levels of formal education are usually adopted as proxies for human capital (eg. Romer, 1993). It would be better perhaps to use these percentages for the labor force but constant changes of its size have made the collection of such data extremely difficult, and when available they either cover recent periods only or areas larger than the regional units of interest.

Barro and Lee (1993) argue that the quality of education which may differ from one area to another should be taken into account. However, this difficulty may be overcome if it is assumed that the quality of the educational system within regions of the same country is similar. The same authors argue that we could weight each level of education with its average rate of market return, but as they acknowledge this may introduce bias in the construction of a human capital index. Causes of bias are the correlation of the level of education with individual skills, and the fact that positive externalities of human capital are ignored by market returns. In general, finding weights for the different levels of education is a difficult task. Moreover, if other forms of training such as the one on the job are also considered for the construction of an index, there will be a need to weight those too.

Many studies have focus on the role of education on growth, regional economic convergence, and on various factors influencing growth and convergence (Kyriacou 1991, Barro 1992, Mankiw, Romer, and Weil 1992, Lee and Lee 1994, Wolf 2000, Bassanini and Scarpetta 2002, etc). Other studies deal with the accumulation and regional convergence of human capital itself. In an International Monetary Fund study for example, Sab and Smith (2001) investigate human capital and health indices convergence for 100 countries and for the period 1970-1996. They find significant $\beta$ convergence and a strong positive relationship between health and human capital indices. In addition, Coulombe and Tremplay (2001) find both $\sigma$-convergence and $\beta$ convergence for human capital in the regions of Canada during the period 1951-1996. However, the speed and magnitude of convergence varies for different levels of educational achievement and for different age groups.

As a rule, years of schooling or levels of formal education are used in the referenced studies as proxies, to capture human capital accumulation and its variation. Following the usual practice in the literature and given the availability and consistency of data series available, we use two different indices of human capital for the 51 Greek prefectures and for the census years 1971, 1981, 1991 and 2001. One index is the percentage share of population 20 years old and above, which has completed secondary education, i.e. 12 years of formal schooling. The other index is the percentage share of population 25 years old and above which has completed university education. Statistical data and information were collected from the surveys and publications of the National Statistical Service of Greece.

Therefore, the population included in the first index is also included in the second. Naturally, the latter includes the population which has completed post-graduate level education as well. Graduates of the various vocational and higher level professional schools and institutes, which require for admission secondary education degrees but they are not officially considered equivalent to universities, are included in the first 
index. That was the best alternative treatment for these institutions given the substantial occurred changes in the structure of their network and their legal and institutional framework of operation. In any case, the nature of accessible data at the level of prefecture and their compatibility influenced the adoption of the certain indices.

\section{Quantitative Analysis}

Greece came out of WW II and subsequent political unrest and a civil war that ended in 1949 with a battered economy and a largely destroyed infrastructure. Primary schools were not available in all rural villages and communities, let alone secondary education schools. Economic difficulties prevented many young people from attending high school. Others had to commute to distant places in order to attend classes and quite often these distances were prohibitive. Conditions were much better at urban centers and near them, where access to secondary education was easier. Access to the limited positions available at the universities was even more difficult. High school graduates from low income families were forced by economic conditions to acquire a source of income instead of preparing for entrance to the university. Moreover, university education was not completely publicly funded until 1964, and student fees had to be paid. Understandably, it was even harder for the larger part of potential students to pursue university education abroad.

By the beginning of the period examined in 1971, the situation had improved substantially. Economic conditions and geographic access to secondary education were both improving. A larger part of potential students especially from rural areas could compete for and gain access to university education. Old problems were persisting to a significant extent but since then substantial progress was further achieved. In addition to increased real incomes, greater expansion of the secondary education system facilitated access. New schools were added to the system, not only to facilitate geographic access in rural areas but also to accommodate rapid urbanization that accompanied Greece's post war growth. Similarly, expansion of the university system facilitated access to university education too, while economic conditions made foreign university education affordable to a rising number of households.

In 1971 the percentage of persons 20 years old or older with completed secondary education was only $17.20 \%$ but in 2001 was increased to $48.49 \%$. The percentage of persons 25 years old or older with completed university education was only $4.01 \%$ but it was increased to $12.19 \%$ in 2001 . There is a clear increasing trend from one census year to another for the two human capital indices and the trend is sharper for the index of secondary education and for the examined period 1971-1981.

Persistent regional economic disparities meant that improvements in access to secondary and tertiary education and their subsequent benefits were not equally felt in all parts of Greece. Prefectures that include highly populated urban areas display the highest values of the two indices. This is especially true for the prefectures of Attica and Thessaloniki which include the two most populated cities of the country, Athens and the city of Thessaloniki respectively. The two prefectures have the highest index values in all census years considered and for both indices. In 1971 the values of their secondary education indices were $30.29 \%$ and $23.67 \%$ respectively. In 2001 they had 
become $61.68 \%$ and $56.59 \%$ respectively. The values of the university education indices which were $6.67 \%$ and $4.85 \%$, in 1971 had become $16.97 \%$ and $15.93 \%$ respectively in 2001. On the other hand, prefectures such as Evritania and Rodopi with a per capita income among the lowest in Greece, display also human capital indices among the lowest in Greece. In Evritania, at the beginning of the period only $4.45 \%$ of the population with age 20 or older had completed secondary education and only $1.89 \%$ of the population 25 years old or older had completed university education. In 2001 the respective percentages were $28.96 \%$ and $5.73 \%$ but Evritania still ranked last in terms of both indices.

Persistent disparities do not imply of course that prefectures have not traded places in the rankings with respect to the two indices. Two success stories for example are the prefectures of Ioannina and Achaia with the two urban centers of the city of Ioannina and Patras. The two prefectures occupy the third and forth place interchangeably with respect to the two indices, at the end of the period. Their relative performance was lower however, at the beginning of the period. The existence of large university campuses has certainly influenced the relative performance of the two prefectures.

\section{$\underline{\beta \text {-convergence }}$}

It seems reasonable at first to make the frequent assumption of a common steady state for every index between the Greek prefectures, the economy and educational system of which operate under the same legal and institutional framework. Within a country under such conditions, variables that determine the steady state values can be expected to be the same (Aghion and Howitt, 1998). Based on this assumption, preliminary results of econometric analysis are obtained using cross-section data. In particular, cross-section analysis was conducted for the period 1971-2001 estimating (6) for the two human capital indices utilizing the 51 observations with $\mathrm{T}=30$ ).

A coefficient of $b$ equal to -0.02 is estimated for the secondary education index, statistically significant at the $1 \%$ level of significance (t-value, -20.78) confirming the existence of $\beta$-convergence, while the adjusted $\mathrm{R}^{2}$ is 0.86 . (Similar results are obtained estimating the absolute convergence model of (6) for the three consecutive decades separately where $\mathrm{T}=10$, with all $\mathrm{b}$ estimates remarkably close and all adjusted $\mathrm{R}^{2} \mathrm{~s}$ lower at $0.492,0.661$, and 0.471 respectively). Results for the university education index differ, but confirm the existence of $\beta$-convergence in this case too. Estimation of (6) for this index and for the whole period 1971-2001 provides a value of -0.013 for $b$ which is statistically significant (t-value, -4.992) and an adjusted $R^{2}$ equal to 0.331. (In this case separate estimates of the model for the three consecutive decades yield different negative values of $b$ and different adjusted $\mathrm{R}^{2} \mathrm{~s}$ while for 1991-01 the estimate of $b$ is not significant at the 5\% level). In all these estimations heteroscedasticity was not present.

Nevertheless, the assumption of a common steady state may not be correct. In this case the estimation of a conditional convergence model requires augmenting (6) with other constraint variables for which data may not be sufficiently available at the prefecture level. In addition, cross section analysis has been criticized on other grounds too. Quah $(1993,1996)$ who dismisses the concept of $\beta$-convergence since it doesn't imply reduction of the distribution's dispersion ("Galton's fallacy"), argues that econometric problems lead in a mechanistic way to the frequent repetition of a 
0.02 estimate for the rate of income and productivity convergence in many studies. Moreover, cross section analysis does not capture the dynamics of the convergence process, something which time series analysis attempts to do if time series data are available, but not without its own methodological problems too (Durlauf and Quah, 1999). It is also argued that low rates of convergence in cross section studies reflect bias due to lack of accounting for unobserved differences between the cross sectional units (de la Fuente, 2000).

The use of panel data allows for the better understanding of the dynamic process of convergence and improves the quantity and quality of available data. Unobserved regional effects can be introduced as variables fixed with respect to time which would not be possible in cross sectional analysis (Temple, 1999). Therefore, heterogeneity between cross sectional units can be accounted for with variables independent of time, increasing simultaneously the degrees of freedom and information available and allowing for the study of the dynamic change from one situation to another (Baltagi, 2001). The use of regional dummy variables in the fixed effect panel data model allows for different steady states. The dummies capture the impact of the actual variables affecting the steady states. In fact they can account for information not conveyed by the additional constraint variables that would have been included perhaps in the model (Miller and Upadhyay, 2002). The same is achieved with the random effects model specification, without the use of dummies.

These arguments have led to a variety of economic convergence studies using approaches of panel data analysis assuming a common steady state or not (Mankiw, Romer, and Weil, 1992, Knight, Loayza, and Villanueva 1993, Loayza 1994, Islam, 1995, Lee, Pesaran, and Smith, 1997, etc). In the study of Coulombe and Tremblay (2001) on human capital convergence in Canada, a common steady state is assumed based on the Aghion and Howitt (1998) argument since provinces of the same country are examined. As a consequence, in their study cross section and time series data are pooled without consideration of possible space or time effects. Their GLS results confirm the existence of $\beta$-convergence for the different sexes, age groups, the population as a whole, and for the different indicators based on formal educational achievement. Moreover, an invoked series of studies for Canada with different quantitative approaches has validated the absolute convergence model for income per capita, income per unit of labor and other productivity indices, advocating for common steady states for these variables (Coulombe and Lee 1993, 1995, Lee and Coulombe 1995, Coulombe and Day 1999).

Tsionas (1992) found the existence of $\beta$-convergence for the Greek prefectures during 1971-1993 and $\sigma$-convergence only for 1982-1993 when the speed of convergence was higher as well. Papadas and Efstratoglou (2002) found $\beta$-convergence using cross sectional analysis for the period 1971-1991, for the three interim decades with different estimated rates, and $\sigma$-divergence. Their results seem to validate the absolute convergence model since a number of constraint or conditioning variables were not found significant. However, data on several constraint variables usually adopted in the conditional convergence model, were not available at the prefecture level and proxies were used. Panel data analysis provides some evidence in support of the $\beta$ convergence model for output per unit of labor in Greece during the period 1971-2001 with significant time effects, while space and time effects are separately considered 
(Vlassis, 2008). Human capital convergence in Greece is a subject much less dealt with.

It is worth noting that overwhelmingly, panel data convergence analyses of economic or human capital indicators, either assume a common steady state when regions or examine the significance of regional effects to conclude and capture differences in steady states. Time effects are not usually considered. This is true for studies referenced above while there seems to be also a preference for the fixed effects over the random effects model (eg. Miller and Upadhyay, 2002) since the latter assumes that space or time effects are not related to the initial state which is considered unrealistic. We conduct our panel data analysis assuming first, a common steady state. Then we examine the significance of regional and time effects and derive again estimates on $\beta$-convergence. The existence and estimates of $\beta$-convergence are analyzed. Moreover, the performance of the fixed versus the random effects model is examined too.

With a common steady state as in Coulombe and Tremblay (2001), the three time period cross section data can be pooled together and an equation of the form of (6) can be estimated again, with $\mathrm{T}=10$ and 153 observations. Table 1 presents some of the estimated GLS results:

Table 1: Absolute Convergence Estimates (pooling with no space or time effects)

\begin{tabular}{|l|l|l|l|}
\hline Parameters & a & b & $\bar{R}^{2}$ \\
\hline secondary education & 0.006 & $\begin{array}{l}-0.023 \\
(-26.63)\end{array}$ & 0.736 \\
human capital index & $(3.03)$ & $\begin{array}{l}-0.010 \\
(-2.15)\end{array}$ & 0.030 \\
\hline university education & $\begin{array}{l}0.007 \\
\text { human capital index }\end{array}$ & $0.43)$ & \\
\hline
\end{tabular}

Estimates of the coefficients and adjusted $\mathrm{R}^{2}$ are given at the appropriately labeled columns (as expected, for these particular equations the simple and adjusted values of $\mathrm{R}^{2}$ are similar), and numbers in brackets are the t-values. The results for the university education index confirm the existence of a significant at the $5 \%$ level $\beta$-convergence, but the important result is the very low goodness of fit of the absolute convergence model. The model for the secondary education index performs better as the adjusted $\mathrm{R}^{2}$ suggests. The estimated coefficient of the initial state and therefore the speed of convergence as well, are higher than in the case of the university education index and significant at the $1 \%$ levels. The constant term is also significant at the $1 \%$ level unlike the case of the university index.

Assuming that steady states may differ, we examine first the statistical significance of possible space effects for the fixed effect model. Maintaining the constant term, regional dummies equal to the number of prefectures less one are added to the previous model based on (6), with the pooled data $(\mathrm{T}=10)$. Estimates of this fixed effect model for the two indices are given in Table 2. 
Table 2: Conditional Convergence Estimates (pooling with fixed regional effects)

\begin{tabular}{|c|c|c|c|}
\hline Parameters & $\mathbf{a}$ & b & $\bar{R}^{2}$ \\
\hline $\begin{array}{l}\text { secondary education } \\
\text { human capital index }\end{array}$ & $\begin{array}{l}0.007 \\
(2.65)\end{array}$ & $\begin{array}{l}-0.022 \\
(16.39)\end{array}$ & 0.69 \\
\hline $\begin{array}{l}\text { university education } \\
\text { human capital index }\end{array}$ & $\begin{array}{l}0.003 \\
(0.14)\end{array}$ & $\begin{array}{l}-0.011 \\
(-1.73)\end{array}$ & -0.385 \\
\hline
\end{tabular}

Accounting for space effects reduces the fitness of the model and the statistical significance of the estimates. (The negative adjusted $R^{2}$ corresponds to an $R^{2}$ of 0.08 up from 0.029 in the previous case). In the case of the university education index the reduced now coefficient of the initial state is not significant at the $5 \%$ level but remains negative and significant at $10 \%$, which is insignificant "evidence" of $\beta$ convergence. The latter continues to take place at a higher rate in the case of secondary education index and remains statistically significant at the $1 \%$ level. The Fvalue for the space effects in the secondary education index case is $F_{(50,101)}=0.551$, which means that at $1 \%$ level of significance the null hypothesis that regional effects or regional dummies as a group are zero, cannot be rejected. Similarly, the F-value for regional effects in the regression for the university education index is $F_{(50,101)}=0.109$ and the null hypothesis cannot be rejected and as a group, regional dummies should be considered negligible.

These results would imply that there is a common steady state and absolute $\beta$ convergence. However, in the case of university education the model displayed poor fitness. In addition, considering the absolute convergence model or the model with regional effects, as is a common practice in a large part of the convergence literature, should not be enough necessarily, for panel data analysis. Time effects should be considered too which in our case for the fixed effect model implies the use of two dummies if the constant term is to be maintained. Table 3 presents the results of a tentative estimation when only time effects are included in the model.

Table 3: Estimates when Pooling with Time Effects

\begin{tabular}{|l|l|l|l|}
\hline Parameters & a & b & $\bar{R}^{2}$ \\
\hline $\begin{array}{l}\text { secondary education } \\
\text { human capital index }\end{array}$ & $\begin{array}{l}-0.002 \\
(-0.45)\end{array}$ & $\begin{array}{l}-0.027 \\
(-13.17)\end{array}$ & 0.752 \\
\hline university education & $\begin{array}{l}-0.038 \\
(-2.492)\end{array}$ & $\begin{array}{l}-0.023 \\
(-5.192)\end{array}$ & 0.725 \\
human capital index & &
\end{tabular}

There is significant $\beta$-convergence in terms of both indices at the $1 \%$ level. There is a similar estimated value of $b$ for the secondary education index in all regressions presented so far around -0.02 . The estimated coefficient for the university education index is around -0.1 for the first two panel data regressions but is insignificant in poorly fitted equations. The inclusion of time effects raises the absolute value of the estimated coefficient $(-0.02)$ to same levels as for the secondary education and more important, it makes the coefficient significant and improves substantially the fitness of the model. This is a sign of the importance of time effects in this case. Indeed, the Fvalues for the time effects as a whole are $\mathrm{F}_{(2,149)}=5.75$ for the secondary education index and 193.83 for the university education index. Time effects are significant at $1 \%$ level of significance.

Continuing, we examine the existence of $\beta$-convergence in the presence of both space and time effects (regional and time dummies). If time effects are significant, their 
absence in the previous models introduces bias in the estimates of regional effects. The derived results are given in Table 4 .

Table 4: Estimates when pooling with regional and time effects

\begin{tabular}{|l|l|l|l|}
\hline Parameters & $\mathbf{a}$ & $\mathbf{b}$ & $\bar{R}^{2}$ \\
\hline $\begin{array}{l}\text { secondary education } \\
\text { human capital index }\end{array}$ & $\begin{array}{l}-0.08 \\
(-6.39)\end{array}$ & $\begin{array}{l}\mathbf{- 0 . 0 6 6} \\
(-10.567)\end{array}$ & $\mathbf{0 . 7 9 8}$ \\
\hline $\begin{array}{l}\text { university education } \\
\text { human capital index }\end{array}$ & $\begin{array}{l}-0.336 \\
(-12.494)\end{array}$ & $\begin{array}{l}\mathbf{- 0 . 1 1 2} \\
(-14.01)\end{array}$ & $\mathbf{0 . 8 6 3}$ \\
\hline
\end{tabular}

The inclusion of both effects in the estimated equations for the two indices improves clearly their performance. Coefficients of the initial state have risen substantially as is often the case in panel data analysis when both effects are considered. Both are significant and the adjusted $\mathrm{R}^{2}$ is higher for both estimations. This is especially true for the case of university education index where the results present the most impressive change when time and now both effects are captured. This reflects the high rate of $\beta$-convergence as economic conditions were improving and university education was becoming more easily accessible to a larger part of the population from all areas, and the particularities of space and time must be considered.

The above conclusion is based on conducted $\mathrm{F}$ tests for regional effects and time effects as separate groups, when both are included. Tests showed that each group is statistically significant. In the case of secondary education index the space effects are significant at the 5\% level with a value of $\mathrm{F}=1.688$ and the time effects are significant at the $1 \%$ level with $\mathrm{F}=28.127$ (if both effects are considered together as one group they are significant at $1 \%$ ). Exactly similar conclusions on statistical significance are derived for the groups of effects separately examined, in the case of the university index too. The space effects are significant as in the secondary education index with $\mathrm{F}=4.001$ and the time effects with $\mathrm{F}=461.51$ (the same as before conclusion holds for the case when both are together examined). Even in terms of fitness the model with the two effects and for both indices performs better than all other panel data models discussed.

The results of the process followed clearly show that both regional and time effects should be included in the estimated model for the two indices. There is conditional $\beta$ convergence and both human capital indices for each prefecture convergence to their own steady states which in general differ. The significant time effects however imply that steady states in general are subject to change over time. This is obviously an important result since it may alter in the future the differences between regional steady states or eliminate them. This result makes our estimates a picture of the past and, without more information on the pace of steady state change, questions their inter-temporal validity. The significance of time effects reduces the value and volume of information provided by $\beta$-convergence analysis but this is certainly no reason for ignoring them. Enriching the model to analyze and consider the change of steady states becomes important, as becomes perhaps the possibility of different $b$ estimates for different regions.

No reference has been made so far to results with the alternative approach to panel data analysis, often pre-excluded for mentioned reasons, the random effects model. This is because this approach was considered too but the fixed effect model was found 
superior. The whole process was applied to the random effects model and the results in terms of statistical significance for space and time effects were exactly the same. The conclusion that both effects should be considered in the model is verified with the random effects model too and this is true for both indices. First, with both effects included, the random effect model is outperformed by the fixed effect model in terms of adjusted and simple $\mathrm{R}^{2} \mathrm{~s}$ which are almost the same in the random effects model due to its structure ( 0.58 for the secondary education index and 0.155 for the university education index). The Hausman test also shows that the fixed effects model is preferred to the random effects model with a value of $X^{2}=46.22$ when both space and time effects are included (in fact with this test the preferred fixed effect model is also superior to the other random effects models with space only or time effects only).

Discussed limitations of $\beta$-convergence, especially in light of our results on time effects, give particular importance to the examination of distributional characteristics and their changes to which we now turn.

\section{$\underline{\sigma \text {-convergence }}$}

We present in Table 5 standard deviation estimates for the four census years and for the two distributions of the two human quality indices.

Table 5: Standard Deviations of the

Human Quality Indices Distributions

\begin{tabular}{|c|c|c|}
\hline Year & $\begin{array}{l}\text { Secondary education } \\
\text { human capital index }\end{array}$ & $\begin{array}{l}\text { University education } \\
\text { human capital index }\end{array}$ \\
\hline 1971 & 0.043 & 0.008 \\
\hline 1981 & 0.053 & 0.012 \\
\hline 1991 & 0.059 & 0.016 \\
\hline 2001 & 0.065 & 0.022 \\
\hline
\end{tabular}

Overall, as expected standard deviations are significantly higher for the secondary education index than for the university education index. The estimates presented show that the distributions for both indices are characterized by $\sigma$-divergence in each decade and also for the whole period. The dispersion of the distributions as measured by standard deviations is increasing constantly for both indices. The speed by which this divergence occurs is not constant. The observed $\sigma$-divergence for the secondary education index is greater during 1971-1981 where the value of $\sigma$ increased by $23.3 \%$, while for the subsequent decades the percentage changes of $\sigma$ are $11.3 \%$ and $10.2 \%$. The same is true for the of the university education index where $\sigma$ increased by $50 \%$ during the first decade while the subsequent increases were $33.3 \%$ and $37.5 \%$. Hence, even though divergence is increasing for the secondary education index, the rate of increase is diminishing. This is not exactly true for the university education index which presents some fluctuation in the rate of divergence increase, but again this remains below the high rate of the first decade.

For the whole period, standard deviations increased by $51.2 \%$ for the secondary education index and by $175 \%$ for the university education index. Divergence is much larger for the university education index. 
Estimates of the Pesaran pairwise differences indices as measures of distribution dispersion were calculated, for both human capital distributions. Table 6 below shows estimates using the absolute values form of (9b). Estimates based on (9a) are not presented here since this form is directly and strictly related to standard deviation with the formula presented above.

Table 6: Pair-wise Differences of the

Human Quality Indices Distributions

\begin{tabular}{|c|c|c|}
\hline Year & $\begin{array}{l}\text { Secondary education } \\
\text { human capital index }\end{array}$ & $\begin{array}{c}\text { University education } \\
\text { Human capital index }\end{array}$ \\
\hline 1971 & 0.037 & 0.008 \\
\hline 1981 & 0.050 & 0.010 \\
\hline 1991 & 0.060 & 0.015 \\
\hline 2001 & 0.069 & 0.021 \\
\hline
\end{tabular}

The estimates show that with this criterion too, dispersion of the distributions of human capital has been increasing and therefore divergence is concluded. Dispersion using this index as a criterion is again greater for the secondary education index than for the university education index. However, looking at percentage changes we see again that in general and for the whole period dispersion is increasing much more rapidly for the university education index, with the only exception the decade of 1971-1981. The Pesaran index increased during the whole period by $86.5 \%$ for the secondary education index and by $162.5 \%$ for the university education index.

The percentage increases of the pairwise differences index for the secondary education index $(35.1 \%, 20 \%$, and $15 \%)$ are diminishing and therefore divergence is increasing at reducing rates. The same is not true for the university education index $(25 \%, 50 \%$, and $40 \%)$ where the rate of divergence presents fluctuations. Compared with the standard deviation approach, this one implies a larger divergence for the secondary education index but a somewhat lower divergence for the university education index, for the whole period.

\section{Q-convergence}

Using the concept of Q-convergence we calculate and present in Table 7 estimates of the IQR changes for the two distributions. The concept used does not measure dispersion but changes in dispersion. For this reason estimates are given for the three decades instead of census years and for the whole period as well.

Table 7: IQR changes of the Human Quality Indices Distributions

\begin{tabular}{|l|c|c|}
\hline Period & $\begin{array}{l}\text { Secondary education } \\
\text { human capital index }\end{array}$ & $\begin{array}{c}\text { University education } \\
\text { Human capital index }\end{array}$ \\
\hline $1971-1981$ & 0.022 & 0.003 \\
\hline $1981-1991$ & 0.015 & 0.005 \\
\hline $1991-2001$ & 0.004 & 0.003 \\
\hline $1971-2001$ & 0.041 & 0.010 \\
\hline
\end{tabular}


According to our definition of the Q index and IQR the estimated numbers show the change in the value range of the $50 \%$ of observations around the median. Estimates are based in (7) and since all numbers are positive we can conclude that during every decade and for the overall period. Q-divergence is observed for both human capital indices. This occurs with regards to both human capital indices. The results in Table 7 agree with the previous findings on divergence and increasing dispersions.

Since our Q index measures absolute IQR changes, we cannot derive conclusions on the rate of divergence. To account for this fact, we suggest using the percentage change in the IQR for the decades and the whole period. This is given by $\left[U_{1}-L_{1}-\left(U_{0}-L_{0}\right)\right] /\left(U_{0}-L_{0}\right)$. Q-divergence occurs, declines in absolute size for the secondary education index and presents fluctuations for the university education index. Using the last formula it is concluded that Q-divergence occurs at a reducing rate for both indices. The results for the three consecutive decades and for the secondary education index are $84 \%, 32 \%$ and $0.06 \%$ while for the university education index they are $49 \%, 46 \%$, and $18 \%$. For the whole period the result is $61 \%$ for both human capital indices. Minimizing the role of outliers has probably differentiated these results compared to previously estimated rates of divergence and now this is found diminishing faster.

\section{Conclusions}

Human capital convergence in Greece at the level of prefecture (NUTS III) has been considered. Two human capital indices and their distributions were examined. One is the percentage of population with completed secondary education and the other the percentage of population with completed university education. Data were available for the census years of 1971, 1981, 1991 and 2001 for all 51 prefectures considered.

Conducting panel data econometric analysis and assuming a common steady state, evidence of absolute $\beta$-convergence was found even though the model performed poorly in the case of the university education index. When allowing for different steady states including regional effects, these effects were found insignificant for both indices. However, continuing the process of achieving the best specification, the inclusion of time only effects showed that these effects were in both cases significant. Subsequently, the inclusion of both effects in the model clearly showed that both effects are significant and the model achieved also its best performance.

Regional and time effects should be included in the model. Significant conditional $\beta$ convergence of prefectures' human capital to their own steady states is derived, but the significance of time effects indicates that steady states as group do not remain constants. This may be reducing the amount and value of information provided by $\beta$ convergence estimates but cannot be ignored. It is argued that this may be the case also in several studies that assume common steady states or consider only regional effects to investigate for conditional convergence. Future research should focus on different estimates of the initial state coefficients and impacts, as well as time effects, for the different regions. This could be achieved using sufficient panel data and alternative specifications of the model.

In any case, the evidence of $\beta$-convergence is accompanied by evidence of actual divergence between the Greek prefectures with respect to both human capital indices. 
Three different measures show that human capital divergence between prefectures is increasing. It is increasing at a reducing rate however for the secondary education index while for the university education index we cannot be conclusive, since reduction in the rate of increase is found only with a version of one measure only.

Nevertheless, the continuous regional divergence of human capital constitutes a serious impediment to economic convergence. Given the discussed significance of human capital in growth and convergence, it is very doubtful that observed increases in dispersion of per capita incomes, i.e. income divergence, will be reversed without a reversal of the human capital divergence process. Even though opportunity for education has expanded in all areas, for many years urban areas were in an advantageous position and some still are. A large part of educated persons have not been returning to their place of origin once they complete their formal education. Urbanization and its causes have seriously affected this trend. This is probably the reason for finding rapidly reducing rates of divergence increase, when minimizing the role of urban outliers using the concept of Q-convergence. The results with the other two approaches seem to agree more with the $\mathrm{Q}$ indices when outliers are left out of the analysis. Measures of distribution dispersion become smaller then, but the trends of increasing human capital divergence remain unchanged.

Increases in observed divergence, despite $\beta$-convergence, can be explained by significant differences in initial states, and possibly by differences and changes in steady states. The large difference in convergence coefficients between the two indices of human capital may reflect the nonlinearities of the convergence process. Differences between initial states and most probably between initial and steady states are higher for the university education index than for the secondary education index and this may contribute to a higher rate of $\beta$-convergence for the former than the latter.

The changing rates of divergence and the possibility for its reversal make future research on the subject particularly interesting. Availability of more observed distributions will allow the use of non parametric techniques to study the distributional dynamics and the significance of our findings. Different $\beta$-convergence estimates for different regional units and the subject of changing steady states can also be addressed more thoroughly using alternative econometric specifications.

Human capital divergence should be a regional policy problem for Greece. Regional policies aiming at economic revival of lagging regions and rural development policies attempting to diversify economic activity in rural areas have serious human capital implications for the targeted areas. These must be considered. The kind and size of human capital accumulation they encourage is an important factor of their long run success. In effect, regional human capital accumulation and equity must be one of the targets rather than a mere consequence of regional policies, when such policies are planned.

\section{References}

Aghion, P \& Howitt, P (1998), Endogenous Growth Theory, MIT Press, Cambridge, MA. 
Baltagi, BH (2001), Econometric Analysis of Panel Data, $2^{\text {nd }}$ ed. New York: John Wiley \& Sons.

Barro, RJ (1992), Human capital and economic growth, In: Policies for long-run economic growth, A Symposium sponsored by The Federal Reserve Bank of Kansas City, 199-216.

Barro, RJ \& Sala-i-Martin, X (1992), Convergence, Journal of Political Economy, 100:2, pp. 223-251.

Barro, RJ \& Lee, JW (1993), International comparisons of educational attainment, Journal of Monetary Economics, 32, 363-394.

Barro, RJ, Mankiw, G \& Sala-i-Martin, X (1995), Capital mobility in neoclassical models of growth, American Economic Review, 85, 1, pp. 103-115.

Bassanini, A \& Scarpetta, S (2002), Does human capital matter for growth in OECD countries? A pooled mean-group approach, Economic Letters, 74, pp. 399-405.

Beaudry, P, Collard, F \& Green, DA (2002), Decomposing the twin-peaks in the world distribution of output-per-worker, Unpublished paper.

Bianchi, M (1997), Testing for convergence: Evidence from non-parametric multimodality tests, Journal of Applied Econometrics, 12, 393 - 409.

Brown, D (1992), Efficiency, capital mobility, and the economic union, In Free to Move: Strengthening the Canadian Economic Union, C.D. Howe Institute, Toronto.

Cohen, D \& Sachs, J (1986), Growth and external debt under risk of debt repudiation, European Economic Review, 30, 3, pp. 526-560.

Coulombe, S \& Lee, F (1993), Regional economic disparities in Canada, University of Ottawa, Research Paper No. 9317E.

Coulombe, S \& Lee, F (1995), Convergence across Canadian provinces, 1961 to 1991, Canadian Journal of Economics, 28, pp. 886-898.

Coulombe, S \& Day, K (1999), Economic growth and regional income disparities in Canada and the northern United States, Canadian Public Policy, 25.

Coulombe, S \& Tremblay, J F (2001), Human capital and regional convergence in Canada, Journal of Economic Studies, 28, 3, pp.154-180.

Deaton, A (1997), The Analysis of Household Surveys, Johns Hopkins University Press, Baltimore, MD.

de la Fuente, A (2000), Convergence across countries and regions: Theory and empirics, Discussion Paper no. 2465, CEPR, London 
Durlauf, SN \& Quah, DT (1999), The new empirics of economic growth, in Taylor, JB \& Woodford, M Handbook of Macroeconomics: North - Holland Elsevier Science, pp. 235-308.

Feldstein, M \& Horioka, C (1980), Domestic saving and international capital flows, Economic Journal, 90, pp. 314-329.

Helliwell, J \& McKitrick, R (1999), Comparing capital mobility across provincial and national borders, Canadian Journal of Economics, 32, pp. 1164-1173.

Islam, N (1995), Growth Empirics: A Panel Data Approach, Quarterly Journal of Economics 110, 1127-1170.

Jones, CI (1997), On the evolution of the world income distribution, Journal of Economic Perspectives, 11, $19-36$.

Kalder, N (1964), Essays on Economic Policy, Duckworth, London.

Kang, SJ \& Lee, M (2005), Q-convergence with interquartile ranges, Journal of Economic Dynamics \& Control, 29, 1785 - 1806.

Knight, M, Loayza, N \& Villanueva, D (1993), Testing the neoclassical theory of economic growth, IMF Staff Papers, 40, 3, pp. 512-541.

Kyriacou, GA (1991), Level and growth effects of Human Capital. A cross-country study of the convergence hypothesis, unpublished manuscript, New York University.

Lee, DW \& Lee, TH (1994), Human capital and economic growth. Tests based on the international evaluation of educational achievement, Elsevier, Economic Letters, 47, pp. 219-225.

Lee, F \& Coulombe, S (1995), Regional productivity convergence in Canada, Canadian Journal of Regional Science, 18, pp. 39-56.

Lee, KM, Pesaran, H \& Smith, R (1997), Growth and Convergence: A Multicountry Empirical Analysis of the Solow Growth Model, Journal of Applied Econometrics 12, 357-392.

Loayza, N (1994), A test of the international convergence hypothesis using Panel Data, Policy Research Working Paper 1333, The World Bank.

Lucas, RE (1988), On the mechanics of economic development, Journal of Monetary Economics, 22, pp. 3-42.

Mankiw, G (1995), The growth of nations, Brookings Papers on Economic Activity, 1, pp. 275-325.

Mankiw, G, Romer, D \& Weil, D (1992), A contribution to the empirics of economic growth, Quarterly Journal of Economics, 107:2, pp. 407-437. 
Miller, S \& Upadhyay, M (2002), Total factor productivity and the convergence hypothesis, Journal of Macroeconomics, 24, pp. 267 - 286.

Romer, PM (1986), Increasing returns and long-run growth, Journal of Political Economy, 94, pp. 1002-1037.

Romer, PM (1993), Idea gaps and object gaps in economic development, Journal of Monetary Economics, 32, pp. 543-573.

Papadas, C \& Efstratoglou, S (2002), Regional Growth and Convergence in Greece (Greek text), $7^{\text {th }}$ Conference of the Agricultural Economics Society of Greece, Agricultural University of Athens.

Pesaran, MH (2004), A pair - wise approach to testing for output and growth convergence, Unpublished Paper.

Quah, DT (1993), Galton's Fallacy and test of the convergence hypothesis, Scandinavian Journal of Economics, 95, pp. 427-43.

Quah, DT (1996), Empirics for Economic Growth and Convergence, European Economic Review, 40, 1353-1375.

Sab, R \& Smith, CS (2001), Human capital convergence: International evidence, IMF Working Paper, WP/01/32, International Monetary Fund.

Silverman, BW (1981), Using kernel density estimates to investigate multimodality, Journal of the Royal Statistical Society, 43 B, $97-99$.

Tsionas, EG (2002), Another look at regional convergence in Greece, Regional Studies, 36, 6, pp. $603-609$.

Temple, J (1999), The new growth evidence, Journal of Economic Literature, 37, pp. 112-56.

Vlassis, N. (2008), Convergence of Labor Productivity in Greece: A Panel Data Analysis, unpublished MSc Thesis, Department of Economics, University of Exeter.

Wolff, EN (2000), Human capital investment and economic growth: exploring the cross-country evidence, Elsevier, Structural Change and Economic Dynamics, 11, pp. 433-472. 
